\title{
Dos modos de concebir la labor intelectual: Foucault y Rorty
}

\author{
Two models of intellectual: Foucault and Rorty
}

\author{
JOAQUÍN FORTANET $^{1}$
}

Universidad de Zaragoza

\begin{abstract}
RESUMEN. Este texto analiza los modelos de intelectual propuestos por Foucault y Rorty. Dos modelos que renuncian a continuar los patrones del intelectual clásico y optan por soluciones totalmente opuestas. El intelectual específico, propuesto por Foucault, hace de su labor una tarea crítica que supone un nuevo modo de pensar las relaciones entre filosofía y política, mientras que el intelectual irónico propuesto por Rorty conduce la tarea intelectual hacia una deserción, hacia la supeditación de la filosofía a la democracia. Dos modos, pues, de concebir la práctica filosófica en nuestro presente que nos llevan hacia la pregunta por la crítica en democracia.
\end{abstract}

Palabras clave: Foucault, Rorty, intelectual, crítica, democracia.

\section{Dos miradas enfrentadas}

Foucault y Rorty pertenecen a dos épocas enfrentadas. Sus aspiraciones intelectuales, radicalmente opuestas, pueden entenderse como símbolos privilegiados del choque entre dos modos de entender la actividad intelectual que llegaron a convivir en los años 80 , obligándonos, de algún modo, a convertirnos en herederos de ese enfrentamiento. Analizar sus concepciones intelectuales responde al interés por entender el lugar exacto, en el aquí y el ahora, desde el que poder seguir
ABSTRACT. This text analyzes the models of intellectual proposed by Foucault and Rorty. These two models resign to keep following the classical pattern of the intellectual and opt for completely opposite solutions. The specific intellectual proposed by Foucault makes of his work a critical task that becomes a new way of thinking the relations between philosophy and politics, while the ironical intellectual proposed by Rorty drives his intellectual activity towards desertion, towards the philosophical subordination to democracy. Two ways, then, to understand practical philosophy in our present time which drive us towards the question of criticism in democracy.

Key words: Foucault, Rorty, intellectual, critical task, democracy.

ejerciendo la actividad intelectual. Desde esta perspectiva, en la cual se identifican los contextos de justificación y descubrimiento, observamos el precipitado del pensamiento foucaultiano en la figura del intelectual resistente como un síntoma de una época y una geografía marcada profundamente por el acontecimiento de Mayo del 68. La crítica radical de todas las formas posibles de dominación, la problematización del poder, la puesta en cuestión de la filosofía y del saber clásicos podrían servirnos para trazar algunos de los gradientes que dan forma a ese 
pensamiento que algunos llamaron posmoderno y que respondía a unas exigencias concretas del contexto de la época.

Sin embargo, la tarea intelectual desarrollada por Richard Rorty se sitúa en otras coordenadas. En plenos años ochenta, Rorty aparece en los Estados Unidos como un intelectual cuyo objetivo no es otro que el de justificar la democracia liberal y orientar toda actividad del pensamiento hacia su defensa. Para dicha defensa, Rorty comparte con el pensamiento del Mayo francés su gusto por la ruptura con la filosofía clásica, la filosofía de los fundamentos, y trata de hilvanar una epistemología que permita escapar de la filosofía de los fundamentos y defender, al mismo tiempo, la utopía liberal.

Este texto pretende sondear ambas posiciones, sus enfrentamientos y complicidades, sus disimetrías y acuerdos. Para realizarlo, se ha optado por presentar las concepciones del intelectual de ambos pensadores de un modo sincrético, es decir, desplegando sus particulares miradas sobre temas básicos con el objetivo de poder medir la distancia entre ambos y las implicaciones políticas y filosóficas que posee esa distancia en nuestro presente.

Parece evidente que ambas posiciones deben mucho a sus contextos respectivos. La época de Foucault, que podría definirse como un intento de transgresión de lo dado a través de la crítica sistemática de aquello que somos, atraviesa sin duda su pensamiento y le permite el impulso necesario para comenzar su camino. Lo inesperado, la resistencia, la confrontación política con los modos tradicionales de hacer política contribuyen a moldear en el pensamiento de Foucault una mirada sobre el presente que jamás renunciará a la inservidumbre voluntaria propia del Mayo. A su vez, la época y el contexto propio de Rorty, definido como el triunfo de la democracia liberal norteamericana tras el fracaso de todas las alternativas posibles — particularmente la ensayada por el Mayo francés - se define como la absorción definitiva de todas las esferas del pensamiento. La solidaridad, la contingencia y la ironía son categorías inspiradas en un cierta izquierda norteamericana que, previa renuncia a toda posibilidad de un sistema alternativo, enfoca todos sus esfuerzos en convertir la democracia liberal en el espacio amable y seductor en el cual las posiciones fuertes, las convicciones y los deberes quedan reducidos a preferencias contingentes de los individuos.

Foucault y Rorty, así, representan dos miradas surgidas de diferentes latitudes que se entrecruzan en un momento histórico en el cual el pensamiento del Mayo francés es consciente de su derrota $\mathrm{y}$, mientras trata de vislumbrar el camino para seguir pensando críticamente, queda enfrentado a la mirada de la democracia liberal, una mirada irónica y seductora que trata de ofrecer, a cambio de sus pretensiones públicas, el último descanso a esa crítica insobornable pero exhausta representada ejemplarmente por Foucault.

Y, a pesar de las absolutas diferencias políticas, filosóficas e incluso morales, las posiciones de Foucault y Rorty comparten un mismo escenario: la necesidad de abandonar los fundamentos clásicos, ya inservibles para ambos. En este punto, en el de la renuncia a la tradición adquirida, encontramos el primer punto de unión y el comienzo de la presentación de sus posiciones acerca del papel del intelectual en el presente. Esta presentación nos llevará a ofrecer similitudes y diferencias de manera simultánea para intentar así configurar de un solo trazo cada una de las miradas, cada uno de los gestos que mejor representan las tareas críticas y filosóficas de ambos pensadores. 


\section{Abandonar a Sartre}

Si tuviéramos que realizar el ejercicio de caracterizar los modelos de intelectual propuestos por Rorty y Foucault, definiríamos sus posiciones como un desplazamiento de la figura del intelectual clásico. Dicho desplazamiento es ejecutado sobre la figura clásica del intelectual universal, representado paradigmática y filosóficamente por la figura de J.P.Sartre ${ }^{2}$ - pero que posee su origen histórico en la figura de Zola ${ }^{3}$ - . Se trata del intelectual de izquierdas comprometido que tomaba la palabra para denunciar la opresión, desvelando la verdad enmascarada por los aparatos ideológicos. Sin duda, se trata de una figura del intelectual heredera de la tradición marxista que tanto Foucault como Rorty se encargan de girar a través de ciertas prevenciones teóricas hacia los supuestos que funcionaban en la figura del intelectual clásico. Así, Foucault afirma:

Durante mucho tiempo, el llamado intelectual de «izquierdas» tomó la palabra arrogándose el derecho de hablar como maestro de la verdad y la justicia. Le escuchábamos, o se hacía escuchar, como representante de lo universal. Ser intelectual, era ser un poco la conciencia de todos. ${ }^{4}$

En torno a la figura del intelectual clásico o universal, se agrupan todas aquellas manifestaciones filosóficas que buscan denunciar el enmascaramiento de la verdad, desvelar la realidad que conduce a la opresión hallando las vinculaciones entre la situación actual y las estructuras sociales mediante una teoría fundamentada racionalmente. El intelectual clásico quiere decir la verdad del mundo y los hombres, y cuenta con medios y fundamentos para ello. En ese decir, está implicada la suerte de los desfavorecidos, la injusticia y la ignonimia. Por ello, el decir no puede contentarse con la mera interpretación del mundo, sino que debe ser un decir encaminado a transformarlo.

El intelectual clásico, convertido en juez de la situación social, decide el camino a seguir en la transformación revolucionaria y ofrece ya sea al pueblo, al proletariado o a la clase social la conciencia de su situación concreta a partir de una teoría abarcadora y universalista. Se trata de aquello que Rorty rechaza bajo el nombre de política de movimiento, es decir, un tipo de acción política que refiere cada situación concreta a una situación abstracta y general producto de una teoría universal unida a una pasión de infinito que provee al intelectual de la creencia de hacer caminar a la sociedad al ritmo de un amplio movimiento espiritual de liberación ${ }^{5}$. Ambas caracterizaciones, tanto de Foucault como de Rorty, coinciden en rechazar la voluntad de verdad, la voluntad representativa y la voluntad universalista de la tarea filosófica que le compete actualmente a la figura del intelectual. La idea que subyace a este rechazo es que la aspiración universalista del intelectual clásico no puede ya dar cuenta tanto de las luchas políticas como de la realidad actual. Que es necesaria una nueva modulación de la tarea del intelectual de acuerdo con las mutaciones teóricas y prácticas que han acontecido.

Así, el nuevo intelectual propuesto por Foucault y Rorty tendrá como primeras características las del rechazo a la voluntad de verdad, universalidad y representación. No hablará en nombre de nadie, no pretenderá tomar su propia idea de bien como universal, no será partícipe de los amplios movimientos del espíritu que ofrecen el fundamento de la liberación:

Cambiemos el juego y digamos que los intelectuales no tendrán nada más que decir acerca de lo que es el Bien. Y que será la gente misma, a partir de análisis de la realidad que les propondremos, la que deberá trabajar 
o conducirse espontáneamente de manera tal que definan lo que es bueno para ellos. El bien, eso se innova. El Bien, no existe, como tal, en un cielo intemporal con gente que sería como astrólogos del bien y que podría decir cual es la naturaleza favorable de los astros. El Bien no está definido de antemano, sino que se practica, se inventa. $\mathrm{Y}$ es un trabajo colectivo. ${ }^{6}$

\section{Los nuevos intelectuales}

Este nuevo tipo de intelectual será concebido, positivamente, como un intelectual específico en términos foucaultianos, y como un intelectual dedicado a las campañas en lenguaje rortyano. Sin embargo, ambos modelos poseen fuertes lazos, ya que tratan de quebrar la universalidad de la tarea del intelectual mediante el recurso a la fragmentación de su actividad. Una actividad fragmentada, efímera, labrada con pequeñas intervenciones sectoriales que responden no a problemas universales como la justicia, sino a cuestiones concretas, a luchas singulares en las cuales la tarea del intelectual cobra un nuevo sentido. Para Rorty, aquello que diferencia los movimientos de las campañas es, precisamente, lo que aleja al intelectual clásico del nuevo intelectual. Las campañas responderán a tareas finitas, que pueden tener éxito o no dependiendo de las circunstancias, pero que en ningún caso responden a motivos más elevados que las propias luchas singulares.

Las campañas, en tanto intervenciones sectoriales y efímeras del intelectual, poseen sentido por sí mismas y no precisan de avales filosóficos universales para ser desarrolladas ${ }^{7}$. De igual modo, el intelectual específico propuesto por Foucault se libera del peso de la universalidad, la verdad y la representatividad y desarrolla su actividad mediante intervenciones concretas en problemas concretos, como un especialista que presta su conocimiento específico para contribuir a una causa. Ya no se trata de reconocer la gran figura del intelectual como aquel maestro de la verdad que ilumina, desvela y orienta la práctica social, sino reconocer una pluralidad de figuras intelectuales en tanto se encuentran implicadas en luchas concretas a través de sus conocimientos específicos y expertos. Hablamos de trabajadores sociales, científicos o abogados más que de filósofos, historiadores o sociólogos. El modelo responde a un saber concreto aplicado a una lucha social. Y, por encima de ello, como afirma Deleuze, se trata de dar una aplicación práctica al rechazo teórico de la representación, que pasa por constatar «la indignidad de hablar por otros» ${ }^{8}$.

La nueva figura del intelectual específico supondrá el logro político y teórico que supone la obligatoriedad de prestar la voz, de que el intelectual no hable en nombre de nadie, en representación de ningún colectivo. La función del intelectual específico, pues, quedará restringida a realizar tareas de diagnóstico sobre situaciones concretas surgidas de la voz y las práctica de otros. Diagnósticos que no entrañan ni una apuesta de futuro ni un compromiso con ninguna utopía, sino tan sólo la problematización del escenario concreto, de la problemática específica:

Actualmente, no creo que el intelectual mantenga el papel de decir verdades, de decir verdades proféticas sobre el futuro. Puede que el diagnosticador del presente, como decía anteriormente, pueda intentar hacer comprender a la gente lo que está pasando, en los dominios en los cuales dicho intelectual es competente. A través del pequeño gesto que consiste en desplazar la mirada, el intelectual vuelve visible lo que es visible, hace aparecer lo que está cerca, tan inmediato, tan íntimamente ligado a nosotros mismos que no lo vemos. ${ }^{9}$

Es esta labor de diagnóstico la que resulta crucial a la hora de sondear las funciones del nuevo intelectual propuesto por Foucault bajo la rúbrica del inte- 
lectual específico. El gesto del diagnóstico ${ }^{10}$ entendido como una particular mirada sobre el presente es aquel régimen de mirada orientado a hacer visibles los problemas inmediatos que competen a la problemática concreta. Se trata de una mirada estratégica, empeñada en sacar a la luz las líneas mayores de los problemas inmediatos, los peligros, las formas de actuación que, en virtud de su saber específico, el intelectual juzga convenientes en la coyuntura. Existe un cierto aire pragmático en la consideración de un intelectual de este tipo, en la apertura de la figura de un diagnosticador que se encargaría de analizar el presente con gesto de bisturí, intentando hallar la explicación de los síntomas que se muestran, en su irrupción, desordenados, contingentes y azarosos. Hallar la coherencia de los síntomas en el cuerpo de un diagnóstico es la tarea pragmática del intelectual específico. Pragmática porque no se trata de orientar teóricamente los síntomas sociales hacia una explicación racional como se realizaba en la política de los movimientos denunciada por Rorty, sino de otra cosa: entender los síntomas como una estrategia política del presente contra la cual es posible oponer otra estrategia, con el único fin pragmático de desarticular a la primera. El fin no es otro que la lucha concreta. Sin embargo, la tarea de diagnóstico no se identifica con la política de campañas defendida por Rorty. Puesto que el diagnóstico implica una tarea ontológica y crítica que, al contrario que las campañas, no tiene por objetivo el futuro cercano, sino que comienza y se agota en el presente.

Para Rorty es necesario renunciar a un análisis del presente que busque elementos causales a la hora de comprender lo que nos pasa. Ya no se trata, como en el caso del intelectual específico, de analizar el presente para apuntalar las resistencias, ni siquiera de analizar el presente para apuntalar las reformas mediante la problematización de las causas y las consecuencias. La cuestión misma del presente, como horizonte único en el que se inscribían las luchas, es dejada de lado y considerada parte de un movimiento trascendental. El análisis de las condiciones de posibilidad del presente que nos daría la clave para conocer positivamente el lugar exacto de las reivindicaciones y el papel de las reformas dentro de un sistema institucional o de poder entra, para Rorty, en conflicto con la posibilidad de una acción política pragmática. La acción política pragmática se encuentra únicamente orientada a mejorar la sociedad, pero no la sociedad presente, sino la sociedad futura. Se trata de contribuir, mediante una campaña específica y pragmática, al fomento de la utopía liberal. El campo de juego del intelectual queda, pues, restringido y se anula la posibilidad de un análisis del presente como parte de una estrategia política:

Si queremos que el discurso de los intelectuales del próximo siglo sea interesante y diferente, podemos intentar olvidarnos del posmodernismo y los movimientos y aferrarnos a las campañas. Esto significaría [...] dejar de preguntarnos por la cuestión que, como Foucault señaló agudamente, dominó el pensamiento político de Kant: la cuestión acerca del significado del «hoy» [...] Significaría limitar las preguntas sobre el hoy a los intentos empíricos de predecir el futuro [...] Es un alejamiento de la pregunta trascendental «¿Cuáles son las condiciones de posibilidad de este momento histórico?», y el acercamiento a la pregunta pragmática: «¿cuáles son las condiciones causales para remplazar la actualidad por una mejor actualidad futura?» ${ }^{11}$

\section{Cómo modificar el presente}

Las campañas, en tanto único medio de acción política de los intelectuales, responden a una acción sectorial y específica basada en reivindicaciones concretas que es realizada sin el apoyo de ninguna 
teoría universalista -movimiento- y sin el apoyo de ningún análisis de las condiciones de posibilidad del presente. De hecho, la campaña, elemento político puramente pragmático, es refractaria a cualquier apoyo teórico que no sea el análisis de su utilidad, es decir, es refractaria a cualquier postulado que contravenga las bases de la ontología de la contingencia. Es necesario recordar que la campaña, labor pública del intelectual, en tanto habita el espacio público, debe cumplir el requisito marcado por el espacio post-filosófico: el abandono de la filosofía. La negativa a la posibilidad de que el trabajo político del intelectual venga dado a través de un análisis teórico del presente se nos presenta con un doble sesgo: por un lado, se trata de cumplir la máxima de la cultura post-filosófica: ausencia de filosofía en lo público. Y, por otro, se trata de desarmar no sólo a la figura clásica del intelectual — figura ya desarmada en los años sesenta- sino a la figura del intelectual específico foucaultiano que, según Rorty, dramatiza los conflictos con el fin de hacerlos converger con sus propias ansias de absoluto, abocando la política a una crítica total que no es más que la traslación pública de los sueños de grandeza privados de cambiar la propia vida. La figura del intelectual específico, privada de su elemento anti-estratégico (de su opción por la resistencia) y privada del apoyo teórico y político que suponía el análisis de las condiciones de posibilidad del presente (su ontología de la resistencia) es transformado por Rorty en un intelectual cuya acción política se limita a las reformas sectoriales que sean consideradas útiles pragmáticamente no para la transformación del presente, sino para la mejora del futuro, respetando, así, la positividad de un presente que se nos aparece como puramente contingente. De este modo, el intelectual rortyano y el intelectual espe- cífico foucaultiano, pese a partir del rechazo del intelectual universal sartreano, mantienen profundas diferencias en cuanto a la tarea a realizar. Si la tarea del intelectual específico la hemos podido definir como la de realizar un diagnóstico del presente, tal diagnóstico es rechazado por Rorty debido a las premisas de su ontología de la contingencia. Una tarea intelectual basada en el reconocimiento de la contingencia debe rechazar la tarea del diagnóstico en cuanto tal diagnóstico se enmarcará, necesariamente, dentro de una explicación causal del presente que remitirá a una ontología de algún tipo. Diagnosticar, dirimir los acontecimientos que labran el rostro del presente, es la tarea de un intelectual para el que la tarea todavía debe seguir siendo necesariamente crítica.

En cambio, asumir la positividad del presente, señalar que su ordenamiento tan sólo se debe a una contingencia, augurar que la tarea no es otra que mejorar este presente a través de reformas que posean la marca de utilidad, ésas son tareas propias de un intelectual que asume su puesto en una cultura post-filosófica, un intelectual que asume la deserción de la filosofía y de la crítica como propias y que opta por referir su actuación a ciertas reformas útiles. Ambos caracteres, el del intelectual rortyano y el del intelectual específico, se nos aparecen claramente en el momento en que comienzan a definirse sus tareas. Entendemos como diametralmente opuestas dos opciones que optan o bien por el análisis del presente como problema o bien por la asunción del presente como signo de una ausencia de problema. Precisamente, la problemática de lo que somos en el aquí y el ahora implica la crítica que no asume el carácter de reformismo y que trata de evidenciar las sujeciones que han forjado aquello que somos. La ausencia de problema en eso que somos aquí y ahora, implica una ta- 
rea de otro sesgo, quizás contrario: asumir el presente como territorio propio y enfocar las propias acciones hacia su mejora. Y la mejora del presente, para Rorty identificado con el presente liberal, no es otra cosa que caminar hacia la consecución de la utopía liberal a través de las reformas sectoriales y útiles que promuevan dicho camino. Así, la crítica y el reformismo serán dos de las características principales de las dos figuras de intelectual que aquí venimos tratando. Dos características que representan el rechazo al sueño platónico del filósofo rey, el del abandono de la figura clásica que marcaba la dirección de las luchas, de los problemas y sostenía en sus hombros el peso de la representación de las voces silenciadas.

El intelectual específico foucaultiano, en tanto intelectual resistente, mantiene con la crítica una relación estrecha. No es posible desanudar la crítica de la tarea de resistencia, de la persecución del poder en su ejercicio. Con ello, es necesario definir el modo en que el intelectual específico asume la tarea crítica no sólo para cubrir debidamente el espacio teórico de dicho intelectual, sino también para observar el aumento de la disimetría con el intelectual irónico rortyano. La crítica es asumida por el intelectual específico a través de dos elementos principales: la subversión y la donación de palabra. A través de estas dos características, el intelectual específico desarrollará su labor crítica de acuerdo con un nuevo modelo: por un lado, diagnosticará el presente a través de un análisis ontológico del mismo. Por otro, a través de dicho análisis, paticipará en las luchas específicas.

Se trata de constatar la indignidad de hablar por los otros, de nunca hablar en nombre de nadie. Nunca hablar por los otros significará prestar la voz a aquéllos que carecen de ella. Que carecen de voz debido a ciertos flujos de poder, a ciertas producciones de poder. Que carecen de voz porque, precisamente, los vencidos carecen de palabra. Así, la principal innovación que supone la labor crítica del intelectual específico frente a la tarea del intelectual clásico es la renuncia a tomar la palabra en lugar del otro y, en cambio, la donación de dicha palabra a los silenciados. Esta toma de palabra, para Foucault, es una intervención social inédita, pues supone la intromisión en el campo de juego político de un discurso que no está reglado por las grandes construcciones teóricas del intelectual clásico, de la política o de las instituciones. Con ello, la crítica que lleva a cabo el intelectual se nos muestra como una tarea de diagnóstico crítica en tanto el material del cual están construidas las luchas en las cuales intervenir es el de la misma resistencia. Y, por otro lado, la intervención es crítica en la medida en que rompe con los usos y costumbres tradicionales del intelectual y pretende una toma de palabra directa de los implicados. Toma de palabra en la cual el papel del intelectual específico no es sino un mediador a través de sus conocimientos específicos.

\section{La función crítica del intelectual}

Concebida así la tarea del intelectual específico como crítica, la tarea del intelectual rortyano resulta claramente antagónica. Pese a que el intelectual irónico comparta la crítica al intelectual sartreano, pese a que su condición de portavoz de los desfavorecidos sea desarmada y evidenciada como problemática, pese a que también comparta el gusto por la sectorialidad, por la especificidad rechazando las grandes cuestiones y las grandes empresas y optando por elementos claros y específicos, por luchas concretas y delimitadas, el intelectual irónico no asume las características críticas del intelectual específico. Ya hemos analizado de qué modo para Rorty las campañas son re- 
fractarias a un análisis del presente. Con ello, la tarea de diagnóstico desaparece del horizonte de tareas del intelectual. Sin diagnóstico que vincule la subversión a un elemento causal del presente, dicha subversión aparece como una irrupción contingente y hostil al entramado cultural, una afrenta al espacio público que garantiza la convivencia de territorios privados. De igual modo, Rorty no aceptará una crítica basada en la subversión y en la donación de palabra que guíe la tarea del intelectual. El intelectual rortyano, al contrario que el intelectual específico, no centrará su actividad en sondear el presente para detectar las luchas adecuadas y el modo de contribuir así a la resistencia contra las instituciones.

El intelectual rortyano basa su carácter específico y sectorial no en las luchas concretas que prefiguran sublevaciones, sino en las campañas. La noción de campaña se aleja tanto de la idea clásica de movimiento de carácter universal como de la noción posmoderna $\mathrm{y}$, particularmente, foucaultiana de la resistencia. $\mathrm{La}$ campaña responde a una intervención sectorial basada en reivindicaciones concretas que sean susceptibles de mejorar la convivencia, esto es, que devengan útiles para hacer nuestro sistema democrático más inclusivo. La idea de la campaña apunta a una serie de actuaciones locales reformistas orientadas a mejorar el funcionamiento de las instituciones actuales con vistas a un futuro cercano. Si la actuación política del intelectual foucaultiano suponía una crítica radical a las instituciones que, según Rorty, se encuentra abocada al fracaso absoluto debido a su ausencia de una propuesta y un horizonte, el intelectual rortyano encuentra en la crítica reformista un modo de mejorar el presente con vistas a un futuro cercano.

Sugiero que dejemos de asumir que la función del intelectual es la crítica radical de las instituciones existentes, una crítica que trata de penetrar hasta las realidades que están bajo las apariencias [...] las únicas críticas de las instituciones existentes que realmente cuentan serán reformistas [...] Pensar de esta manera significaría deshacerse de la esperanza de evitar la complicidad con las instituciones presentes e imaginar qué podríamos obtener, mediante una serie de pasos concretos, de una institución presente para llegar a otra algo mejor ${ }^{12}$.

De este modo, la reforma se convierte en el horizonte práctico del intelectual irónico, sustituyendo la crítica bajo sus formas de subversión y de toma de palabra. Concebir una tarea intelectual crítica con las instituciones existentes es, supone, para Rorty un franqueamiento ilegítimo del espacio público. Recordemos que, para Rorty, la función del intelectual es una función pública $\mathrm{y}$, como tal, debe abandonar las pretensiones privadas de autorrealización, los sueños privados de autonomía, las ideas pertenecientes a los vocabularios últimos sobre el bien. Palabras sagradas como revolución, resistencia o subversión deben quedar sumidas en el territorio de lo privado. Representan una vulneración de la división público y privado. El caso de Sartre, del intelectual clásico, era un referente claro, pues suponía fundamentos que, una vez caídos, rompían la legitimidad del paso de lo público a lo privado.

Sin embargo, para Rorty, el caso de Foucault es más grave, pues suple la falta de fundamentos no con la asunción de la contingencia, sino con la crítica total al presente fruto de la invasión total de sus ansias de sublimidad privada en el espacio público. En contra de estas opciones, el intelectual propuesto por Rorty es un intelectual que interviene políticamente en la sociedad, esto es, en el espacio público. Sin embargo, el carácter de dicha intervención respeta escrupulosamente la división entre lo público y lo privado a través del concepto de reformismo. El reformismo, tarea si se quiere crítica del in- 
telectual irónico rortyano, asume la división público y privado ya que promueve una acción reformista sobre una cuestión sectorial del espacio público asumiendo el carácter contingente de la situación a reformar en el presente. Renunciando a la causalidad, aceptando la contingencia, sustituyendo los sueños de autonomía por la reforma pragmática de cierto aspecto del presente y asegurando la utilidad de dicha reforma para un futuro, el intelectual rortyano cumple a la perfección los criterios de división entre lo público y lo privado. El intelectual rortyano posee un único modo de actuación política: el reformismo. Dicho reformismo, no obstante, debe quedar convenientemente anudado para que pueda habitar un espacio público como el rortyano. Con este objetivo, Rorty precisa de un criterio a la hora de decidir las reformas concretas que serán apoyadas por el nuevo tipo de intelectual. Dicho criterio, una vez abandonada la crítica total y la universalidad de los movimientos, no será otro que el pragmático ${ }^{13}$. Rorty nos presenta una figura de intelectual radicalmente opuesta a la foucaultiana. Nos hemos trasladado desde la figura de un intelectual resistente que pretende dar voz a los silenciados y contribuir a sus luchas mediante sus conocimientos específicos a un intelectual voluble, que cumple a la perfección el diagnóstico de la cultura post-filosófica: ostenta un puesto público en tanto intelectual, ejerce una cierta crítica bajo la formulación reformista $\mathrm{y}$, de este modo, no sólo respeta la división entre lo público y lo privado - esto es, los principios básicos de la democracia liberal rortyana- sino que, además, la promueve y mejora caminando hacia la utopía liberal rortyana.

Quizás, la labor más pura del intelectual específico foucaultiano venga contenida en el trabajo que se realizó en el Grupo de Información de Prisiones, mo- delo de numerosas iniciativas posteriores que, todavía hoy, continúan con su labor política ${ }^{14}$. Además de la politización, de la opción por respetar las sublevaciones, la figura del intelectual específico posee otro rasgo característico que ya hemos apuntado, y que constituirá gran parte de la innovación política del Grupo de Información de Prisiones. La experiencia del GIP, surgida dentro del contexto político de Mayo del $68^{15}$, viene fundada por la toma de palabra de los presos, toma de palabra que dará lugar a luchas que no siguen los esquemas clásicos de participación política, pues suponen la ruptura de las mismas al abrir el esquema político a una toma de palabra inédita y ofrecer la dirección de la lucha a las reivindicaciones de los presos. El intelectual se convierte en un instrumento de esa lucha concreta, poniendo a su servicio los útiles de su saber. Y, este poner al servicio los útiles de su saber, pasa por ofrecer un diagnóstico del presente concreto, marcando los lugares más adecuados en los que insistir para llevar a buen término la lucha. El primer acto del GIP va a consistir en el lanzamiento de una serie de encuestas mediante las cuales los presos y sus familiares hacen constar tanto su indignación por el modo en que se ejerce el poder sobre ellos como reivindicaciones concretas. Reivindicaciones que sorprenden por su carácter aparentemente cotidiano: temperatura del agua de las duchas, derecho a tener radios, practicar deportes, comprar tabaco, beber cerveza, caminar una hora más, etc. ${ }^{16}$. Sin embargo, tras estas reinvidicaciones completamente razonables, hallamos el principio de un escándalo político:

Estas encuestas no están destinadas a mejorar, a endulzar, a volver más soportable el poder opresivo. Están destinadas a atacarlo allí donde se ejerce bajo otro nombre - el de la justicia, el de la técnica, el saber, la objetividad-. Cada una debe ser un acto político. ${ }^{17}$ 
Los efectos políticos de los actos del GIP no se hicieron esperar, y el 5 de diciembre de 1971 comienza, en Toul, una serie de violentas revueltas en las cárceles francesas a causa del estado de las prisiones que continuará en gran parte de Francia ${ }^{18}$. Emergía, pues, un movimiento político sin representación alguna, cuya voz no era otra que la voz de los detenidos que se erguía contra lo intolerable de un poder sufrido en el propio cuerpo. La función del intelectual específico se nos presenta, ahora, de un modo más complejo: no sólo se trata de realizar trabajos sectoriales que puedan contribuir a mejorar las condiciones de un colectivo determinado que se subleva, sino producir, mediante la puesta en acto de los saberes específicos, nudos de resistencia, oposiciones tanto al modo en que se ejerce el poder como a los discursos y prácticas políticas tradicionales. Se trata, en fin, de promover apuestas de politización inéditas y específicas mediante las cuales se puedan oponer resistencias al poder. Tales resistencias siempre serán parciales y efímeras en la medida en que se dan en un presente sin recurso a ningún futuro $\mathrm{y}$, por ello mismo, por estar totalmente inscritas en el presente, la tarea del intelectual específico, para marcar los puntos ciegos en los cuales inscribir las resistencias, debe realizar un diagnóstico del presente. Ello nos remite, de nuevo, a la tarea de una ontología del presente. Conocer, analizar, establecer las condiciones de posibilidad a través de las cuales el presente se constituye como tal. Y el establecimiento de tales condiciones de posibilidad pasará por evidenciar los procesos de saber y poder allí dónde se ejercen, aunque sea bajo otro nombre (humanidad, reinserción, justicia). Con ello, la tarea crítica del intelectual pasa, como la obra entera de Foucault, por el establecimiento de una ontología del presente realizada con el único objetivo de transgredirla.

\section{Una nueva y última pasión: la democracia liberal}

Se nos hace ya evidente que el intelectual rortyano nos ofrece un tipo de intervención social radicalmente distinta de la propuesta por Foucault. Rorty propone la redescripción de esta crítica en el ámbito de lo privado dejando el espacio público como el escenario en el cual desarrollar una serie de reformas que contribuyan al mejoramiento y difusión de nuestra cultura. Rorty concebirá la ciudadanía como un marco común, un léxico común ante el cual, en tanto pertenece el espacio público, el intelectual debe plegarse. Las reformas tan sólo serán útiles cuando correspondan con los intereses de la comunidad que las contempla.

No nos queda otra alternativa que cambiar el papel que los filósofos compartieron con los sacerdotes y los sabios y adoptar una función social que se parece más a la de un ingeniero o un abogado. Al contrario de los sacerdotes y sabios, que podían decidir por sí mismos sus temas, los filósofos contemporáneos, lo mismo que los ingenieros y abogados, deben averiguar cuáles son las necesidades de los que les encargan su trabajo ${ }^{19}$.

En efecto, el papel del intelectual, su función social, viene dado por el sentido en que Rorty entiende la utilidad de las intervenciones políticas. Y, dicha utilidad, no viene marcada por la teoría, ni siquiera por el mismo presente, sino por aquella comunidad en la cual la figura del intelectual cobra sentido. Es así como las reformas del intelectual rortyano convergerán con el ideario político liberal norteamericano y el intelectual rortyano se convertirá, a la postre, en un intelectual de la democracia liberal en función de la cual apoyará aquellas campañas reformistas concretas que resulten útiles para 
acercar el presente a la utopía liberal. Con ello, la función del intelectual, para Rorty, se restringe en el ámbito público a un mero apoyo de las campañas que resultan útiles a la liberal-democracia. Se trata de un campo de actuación tremendamente reducido en comparación con el propio del intelectual universal o el intelectual específico. Sin embargo, tanto el intelectual universal como el específico no respetaban la división entre lo público y lo privado, y por ello mismo su campo de actuación era más amplio. El intelectual rortyano, mientras posee una acción restringida a lo concreto y a la utilidad en lo público, mantiene, en cambio, una hiperactividad en el campo privado. En lo privado ya no se trata de campañas, pues lo privado es el ámbito de la contingencia y la autocreación irónica, completamente refractario a cualquier actuación política. La hiperactividad del intelectual en el terreno privado viene dado por la asunción del papel ironista. Como si en el territorio privado se expresasen, más allá de todo principio ético, las verdaderas pasiones del intelectual rortyano: perfección de sí, creación de vocabularios y metáforas, manipulación de los sentimientos, persuasión de auditorios, descalabro de ídolos y razones, fomento y ejercicio ilimitado de la ironía y redescripción del mundo en virtud de la imagen ofrecida por los propios sueños. De este modo, la antigua pasión del intelectual, la política, queda expulsada de sus funciones y actividades.

El intelectual ironista se adhiere a campañas específicas que nos acercan a la utopía liberal en lo público - y para ello debe actuar al margen de la filosofía- $\mathrm{y}$, en el terreno privado, cumple su labor irónica de autoperfección absolutamente refractaria a cualquier compromiso político. Su hiperactividad en la búsqueda de nuevos vocabularios y metáforas, de nuevos modos de redescribir su mundo, no puede dar cuenta de la pasión política que, desde Platón, mueve el pulso de la filosofía. Ni siquiera filosofías como la de Foucault, heredera de la inversión platónica nietzscheana, renuncian a la pasión política, situándola, con distinto rostro y distinta modulación, en el principio mismo de la mirada filosófica. Aquello que se cumple con el intelectual rortyano es el definitivo abandono de la política. La última intervención política en la filosofía se cumple en Rorty como la deserción definitiva del escenario político. Ya no es posible articular filosofía y política, ambas quedan desgajadas, separadas en dos compartimentos estancos, en lo público y lo privado. Pero, esta separación que se da entre el intelectual reformista - público- y el intelectual irónico — privado_- es sintomática de una defunción: la de la filosofía política misma. El intelectual irónico y reformista es la expresión de una doble renuncia que ahora se anuda vista como parte de un mismo gesto: la renuncia a la filosofía política expresa una doble deserción: deserción de la política y deserción de la filosofía ${ }^{20}$. Pese a que se pueda objetar que la deserción de la política sólo se da en el terreno privado, y la deserción de la filosofía sólo se da en el terreno público, no podemos dejar de suponer que tal división entre lo público y lo privado, tal y como analizamos, no responde a ninguna constatación histórica ni filosófica, sino a una opción política que subraya la necesidad de promover la utopía liberal. Tal utopía se nos revela como el lugar ideal en el cual ni la filosofía ni la política caben. La tradición post-nietzscheana había mostrado, merced a la inversión platónica nietzscheana, la necesidad de derribar los ídolos que articulaban la antigua relación entre filosofía y política, mostrando, para ello, los efectos velados de la voluntad de verdad y de la voluntad de poder que hacían po- 
sible tal articulación. Sin embargo, era posible reformular dicha articulación, y la apertura de las intervenciones políticas en la filosofía y en la práctica social como tarea de un intelectual específico hacían posible un nuevo modo de convergencia entre la política y la filosofía: una filosofía politizada que, como en el caso de Foucault, era expresada trágicamente bajo la llamada a la resistencia. Con Rorty, la deconstrucción entre los lazos del binomio filosofía-política nos ofrece un paso más. A través de la posibilidad de ofrecer una filosofía marcada y gobernada por una mirada política - intervención política en la filosofía- se cumple la deserción de la filosofía y de la política, no debido a un escepticismo relativista o al llamado postmodernismo rortyano - a la inversión de la figura del filósofo-rey-, sino a la intervención política liberal consistente en desarmar la potencia crítica y política de una filosofía que se encierra en la clandestinidad de lo privado, condenada a fomentar la autocreación egoísta y contingente del individuo mientras observa, confinada, de qué modo el espacio público es constituido a través de una política reducida a simples campañas de fomento de la utopía liberal.

De este modo, el intelectual deserta de su más antigua pasión, la política, del mismo modo que deserta de su quehacer filosófico en la medida en que su única tarea pasa por cimentar y apuntalar su ser irónico privado. El intelectual rortyano se nos presenta como un intelectual desertor, que vive su propia deserción como un modo de acercarse a la utopía liberal y a la felicidad que supone cumplir sus propios sueños egoístas de autoperfección. Privado de convicciones, de razones y de coherencia, la labor del intelectual desertor se acopla perfectamente a las exigencias de una nueva sociedad globalizada y espectacular, cimentada sobre el consumo y la volubilidad de los individuos cambiantes e irónicos que toman cada juego del mercado y del poder como un nuevo juego irónico que azuza su capacidad de redescripción y creación, de cambio. El vocabulario último del que reniega el ironista es el nudo de coherencia que mantenía la supervivencia de la batalla política. Sesgada dicha coherencia, sustituida por la ironía y la solidaridad, la batalla política da paso a la paz política en el terreno filosófico: a la deserción. El intelectual desertor, que quizás pueda también ser contemplado como un intelectual específico liberal, cumple los sueños utópicos liberales de la deserción, librando a la política liberal del peso del pensamiento y a la filosofía irónica del peso de la política. Enfrentando a la filosofía a la tarea de lidiar con su propia deserción. Así, la intervención política en la filosofía rortyana que se cumple con la figura del intelectual no sólo supone la deserción de la filosofía, el abandono de la política y la instauración de la redescripción irónica, sino el abandono de la contestación al presente, la asunción, acrítica y derrotada, de lo que nos pasa porque, precisamente, lo que nos pasa excede las atribuciones del sujeto, de la crítica y de la filosofía. El intelectual ironista, cambiante y caprichoso, construido con convicciones contingentes, es la plasmación práctica de la intervención política rortyana en la filosofía, es decir, es la plasmación práctica de la opción política por la democracia, por el poder.

Y, a pesar de todo ello, nunca una opción por el poder ha sido tan sutil y extraña, nunca ha contado con menos presupuestos, menos fundamentos, nunca ha proclamado con mayor énfasis el derribo de toda epistemología, de toda moral deontológica, de la tradición. Nunca una opción política por el poder ha convenido que la falta de justificación es el mejor modo para la conservación y promoción del mismo. Nunca una opción militante 
por el presente ha creído oportuno el vaciado ontológico del mismo, la instauración de la contingencia en todos los ámbitos. Nunca una opción liberal ha insistido tanto y de este modo en el fomento de la solidaridad, y en el carácter inclusivo de la comunidad. Nunca un intelectual funcionario ha tenido como misión el fomento de la ironía privada, el introducir el descrédito de los dioses propios y el ateísmo contra las palabras sagradas en sus conciudadanos. Nunca la política había proclamado la deserción. Y, sin embargo, a través del derribo de los ídolos, la moral y la tradición, a través de la constatación de la falta de justificación teórica de la democracia liberal, a través de la contingencia, la ironía y la solidaridad, el intelectual rortyano realiza un movimiento sinuoso y quizás perverso, un movimiento que nos lleva desde el lugar de las intervenciones políticas, un lugar relativamente conocido tras el análisis foucaultiano y que, en Rorty, toma un sesgo contrario, es decir, la defensa del presente, la opción por el poder. Pero esta defensa del hoy y del aquí, del nosotros los liberales, es consciente de su propia desfundamentación, constituyéndose abiertamente como una opción política sin fundamentos que, mediante la división entre lo público y lo privado, proclama el advenimiento de una cultura post-filosófica, es decir, de una cultura de la deserción. Precisamente, podríamos situar la diferencia esencial de estos dos intelectuales que nos ocupan en el tipo de cultura que ambos asumen. Indudablemente, la cultura adecuada para el intelectual resistente responde a patrones radicalmente distintos a la cultura post-filosófica rortyana.

El intelectual resistente se produce y se gesta en el seno de una cultura filosófica, una cultura en crisis, pero todavía sostenida por los fundamentos de los grandes sistemas filosóficos y políticos: la fe- nomenología y el marxismo. La crítica a los ídolos modernos, a la preeminencia del sujeto, a la epistemología y a las ciencias humanas responde a una actitud crítica a través de la cual el intelectual resistente pretende hacer visibles las relaciones de poder que permanecían veladas, y luchar activamente contra aquéllas que resultan intolerables y evidentes. Sin embargo, su lucha no pasa por los cauces habituales a los cuales está acostumbrado el marxismo o el intelectual clásico. Su donación de la voz, su intento de cortocircuitar el entramado político a través de la irrupción de nuevos colectivos, de nuevas voluntades políticas, responde al anquilosamiento y a la crisis de una cultura y un tiempo. Así, el intelectual específico es un intento de pensar de otro modo, un modo de afrontar una crisis y desvelar nuevos enemigos que antes resultaban inéditos.

Pese a que se levante contra la filosofía, pese a que el intelectual específico utilice la filosofía de la sospecha para, precisamente, sospechar de la filosofía, el lugar del intelectual específico es la batalla contra la solidez filosófica. De hecho, Foucault definía la tarea genealógica e intelectual como la liberación de saberes que se encuentran sujetos, ligados a inmovilidades teóricas que funcionan como grandes marcos ${ }^{21}$. La liberación de fragmentos de saber ponía en cuestión, así, las totalizaciones llevadas a cabo por el discurso. Con ello, la cultura del intelectual específico correspondería a una contra-cultura, pero dicha contra-cultura se enmarca en el seno de una cultura filosófica y política. Sin embargo, la cultura que Rorty defiende como deseable subvierte las relaciones sobre las cuales el intelectual específico fundaba su tarea. La ausencia de solidez teórica, la instauración de la anti-epistemología, la sustitución de la verdad por la justificación, la división entre lo público y lo privado, la concepción retórica y per- 
suasiva del lenguaje, la imposibilidad de trazar una ontología del presente, la ausencia de identidades, la contingencia del yo y de la comunidad, todo ello nos conduce a un escenario en el cual apelar a la fragmentación o las diferencias obliga, cuanto menos, a definir convenientemente los términos que se pretenden oponer a un presente contingente, cambiante, injustificado, líquido. Y es aquí, en esta liquidez, donde el intelectual rortyano arraiga con toda su capacidad irónica. Es el intelectual que se adapta perfectamente a los cambios porque ha renunciado a la coherencia, el intelectual que asume la contingencia como parte de su propio ser y se pliega a las necesidades del poder a través de la propuesta de reformas, el fomento de la solidaridad y la creación privada, en donde cumple los sueños a través de sucesivas redescripciones.

Si ambos intelectuales pueden leerse como dos polos de una cultura llamada filosófica, el intelectual rortyano se nos aparece en una suerte de más allá, como un habitante de las ruinas que hace del territorio desértico y yermo de fundamentos el lugar perfecto para construir una ciudad no ideal, sino una ciudad útil a los intereses que le gobiernan. Y esa ciudad no será una ciudad racional, fundada sobre principios sólidos. Será una ciudad líquida, una ciudad irónica en la cual se satisfagan los deseos privados y cambiantes, donde el sentimentalismo reine en el momento en que se muestre el sufrimiento y ello provoque la unión de una comunidad, una comunidad que permanece unida porque, sencillamente, no hay lugar alguno adonde ir. La ciudad rortyana será una ciudad en la nada, una ciudad de apariencias y, sin embargo, atractiva. Rorty nos ofrece el cumplimiento de una versión del sueño americano a cambio de la filosofía, la política y la derrota de otro viejo sueño. Foucault, sin embargo, todavía nos insiste, nos desvela, todavía resiste y su tarea intelec- tual sigue siendo, hasta el desfallecimiento, la tarea de mostrarnos hasta qué punto resulta intolerable ser aquellos que somos, así, de este modo, aquí y ahora. Pensar de otro modo. Con ello, quizás nuestro presente intelectual se juegue entre estas dos opciones. Entre la democracia y la resistencia. Como si la filosofía, para seguir siendo crítica, se viese obligada a pensarse en conflicto con la democracia.

\section{BIBLIOGRAFÍA}

ARAMAYO, R., La quimera del rey-filósofo, Madrid, Taurus, 1997.

ARTIÈRES, PH., «La prison en procès. Les mutins de Nancy», en Vingtième Siècle. Revue d'histoire, n. 70, Paris, abril-junio 2001, pp. 57-70.

Artières, PH.; Quero, L.; ZANCARINI, M. (eds.), Le Groupe d'information sur les prisions. Archives d'une lutte, 1970-1972, Éditions de l'IMEC, Paris, 2003, pp. 133 y ss.

BADIOU, A., Abrege de metapolitique, Paris, Seuil, 1998.

Bermudo, J. M., Filosofía política III. Asaltos a la razón, Barcelona, Ed. del Serbal, 2005.

Deleuze, G., Registro sonoro del curso Le Pouvoir, 1985-1986, Bibliothèque Nationale de France, Côte: PDC12-705.

- La isla desierta y otros textos, Pre-Textos, Valencia, 2005.

Dreyfuss, G.; Frank, R.; ZANCARINI, M. (eds.), Les années 68: le temps de la contestation, Paris, Complexe, 2000.

Esposito, R., «Confines de lo político. Nueve pensamientos sobre política», Madrid, Trotta, 1996.

Foucualt, M., Le pouvoir, les valeurs et l'intellectuel, U. California, Berkeley, 3 November 1980, San Francisco. Archivo del IMEC, Côte D285.

- Dits et Écrits, vol. III y IV, Paris, Gallimard, 1994. 
- Il faut défendre la societé, Paris, Gallimard, 1997.

ReVEL, J., Michel Foucault. Expériences de la pensée, Paris, Bordas, 2005, p. 135.
RorTy, R., Pragmatismo y politica, Barcelona, Paidós, 1998.

- Filosofía y futuro, Barcelona, Gedisa, 2004.

\section{NOTAS}

1 Doctor en Filosofía por la Universidad de Barcelona y Profesor Asociado de la Facultad de Filosofía de la Universidad de Zaragoza.

$2 \mathrm{Y}$, sin embargo, deberíamos también atender a las palabras que Deleuze dedica a Sartre reconociendo la labor del intelectual universal en una determinada época histórica, su entereza moral ante la opresión. Ver al respecto, Deleuze, La isla desierta y otros textos, Pre-Textos, Valencia, 2005.

3 Foucault, Dits et Écrits, vol. III, Paris, Gallimard, 1994, p. 156

4 Foucault, Dits et Écrits, vol. III, op. cit., p. 109.

5 Rorty, Pragmatismo y politica, Barcelona, Paidós, 1998, pp. 68-69.

${ }^{6}$ Foucault, Le pouvoir, les valeurs et l'intellectuel. Interview with M. Foucault by Michael D. Bess, U. California, Berkeley, 3 noviembre de 1980, San Francisco. Archivo del IMEC, Côte D285.

7 Rorty, op. cit., p. 71.

8 Deleuze, Registro sonoro del curso Le Pouvoir, 1985-1986, Bibliothèque Nationale de France, Côte: PDC12-705.

9 Foucault, Dits et Écrits, vol. IV, Paris, Gallimard, 1994, p. 594.

10 Gesto teorizado por Foucault como «un coup d'oeil» en Foucault, Naissance de la clinique, Paris, PUF, 1963, p. 123.

11 Rorty, Pragmatismo y política, op. cit., p. 78.

12 Rorty, Pragmatismo y política, op. cit. pp. $54-55$.

13 Rorty, Pragmatismo y política, op. cit., p. 79.

14 Un ejemplo cercano es la labor del Observatorio del Sistema Penal y Derechos Humanos de la Universidad de Barcelona. A la hora de ofrecer un antecedente de la experiencia del GIP, debemos remontarnos a la teorización de la práctica de la encuesta realizada por el grupo de la revista Quaderni Rossi, dirigida por R. Panzieri, R. Alquati, M. Tronti y T. Negri. Desde su nacimiento, el GIP estuvo ligado al grupo italiano Soccorso Rosso, fundado por militantes de la extrema izquierda Lotta Continua, manteniendo lazos con los movimientos izquierdistas italianos del Potere Operaio.

15 Sobre la contestación política general y el contexto político de Mayo del 68, ver al respecto, G. Dreyfus-Armand, R. Frank, M. F. Levy, M. Zancarini-Fournel (ed.), Les années 68: le temps de la contestation, Paris, Complexe, 2000.

$16 \mathrm{Ph}$. Artières, L. Quero, M. Zacarini-Fournel (eds.), Le Groupe d'information sur les prisions. Archives d'une lutte, 1970-1972, Éditions de l'IMEC, Paris, 2003, pp. 133 y ss.

17 Foucault, «Préface», en Le Groupe d'information sur les prisions. Archives d'une lutte, 19701972, op. cit., p. 53.

18 Ver al respecto, $\mathrm{Ph}$. Artières, «La prison en procès. Les mutins de Nancy», en Vingtième Siècle. Revue d'histoire, n. 70, Paris, abril-junio 2001, pp. 57-70.

19 Rorty, Filosofia y futuro, Barcelona, Gedisa, 2004, p. 16.

20 Sobre la problemática de las relaciones entre filosofía y política a propósito de la deserción, ver A. Badiou, Abrege de metapolitique, Paris, Seuil, 1998; R. Espósito, Confines de lo político. Nueve pensamientos sobre política, Madrid, Trotta, 1996; R. Aramayo, La quimera del rey-filósofo, Madrid, Taurus, 1997, y J. M. Bermudo, Filosofía politica III. Asaltos a la razón, Barcelona, Ed. del Serbal, 2005.

21 Foucault, Il faut défendre la societé, Paris, Gallimard, 1997, pp. 11-14. 